\title{
Topological Saponification of Oriented Poly(vinyl Trifluoroacetate) to Poly(vinyl Alcohol) with Gaseous Ammonia
}

\author{
By Shuji Matsuzawa, Tetsuya Tanigami, and Qi Wang \\ Faculty of Textile Science and Technology, Shinshu University, Ueda 386 \\ (Communicated by Seizo OKamuRa, M. J. A., June 11, 1996)
}

\begin{abstract}
Drawn poly(vinyl trifluoroacetate) (PVTFA) films were converted into syndiotacticityrich poly(vinyl alcohol) (s-PVA) films through the saponification in solid state with gaseous ammonia. The intensities of crystallization and racemic diad sensitive bands in infrared absorption spectra of the s-PVA films decreased with increasing heat-drawing ratio before saponification. In the s-PVA film prepared from the PVTFA heat drawn before saponification, the intensity of crystallization sensitive band did not change whereas that of racemic diad sensitive band decreased with heating time respectively. This means that the solid s-PVA prepared from heat-drawn PVTFA has the solid structure determined by that of PVTFA, i.e. the low degree of crystallization and high hydrogen bond content. The s-PVA has hot-water resistance and only soluble at temperatures above $100^{\circ} \mathrm{C}$.
\end{abstract}

Key words : Poly(vinyl trifluoroacetate); solid state saponification; syndiotacticity-rich poly(vinyl alcohol); crystallization sensitive band; racemic diad sensitive band; crystallinity.

Introduction. Poly(vinyl trifluoroacetate) (PVTFA) was first prepared in 1956 and the poly(vinyl alcohol) (s-PVA) derived through the saponification of PVTFA was found to be insoluble in water at temperatures below $100^{\circ} \mathrm{C}$ and different from commercial PVA (c-PVA). ${ }^{1)}$ Until 1961 s-PVA was presumed to be syndiotactivity-rich due to the dissolution in water at temperatures above $100^{\circ} \mathrm{C}^{2)}$ and the intense color development of the complex with iodine. ${ }^{3)}$ In 1965-1966 s-PVA was clarified to be syndiotacticityrich from NMR spectroscopy. ${ }^{4)-6}$ The numerical values of the contents of racemic diads were then not precise since the resolution in NMR spectroscopy was low. At present the racemic diad contents of s-PVA samples derived from PVTFA samples bulkpolymerized at $60^{\circ} \mathrm{C}$ and $-78^{\circ} \mathrm{C}$ are decided to be ca. 58 and 64 percent whereas that of c-PVA ca. 54 percent using $400 \mathrm{MHz}$ NMR spectrometer. ${ }^{7), 8)}$ The melting point of a s-PVA is higher than that of c-PVA and increases with increasing syndiotacticity, ${ }^{9)}$ which shows the easy crystallizability of s-PVA. The high performance polyethylene fiber is made of the crystallites with highly oriented molecules. ${ }^{10}$ ) The high performance PVA fiber similar to high performance polyethylene fiber has not yet been prepared due to the prevention of inter and intramolecular hydrogen bonds between hydroxyl bonds. ${ }^{11), 12)} \mathrm{A}$ high performance s-PVA fiber is supposed to be prepared through the saponification in solid state of highly drawn PVTFA fiber.

The saponification of drawn PVTFA with gaseous ammonia had already been reported to give the s-PVA of high order orientation and low degree of crystallization. $^{1), 13)}$ This paper reports on the detailed investigation on the structure of the s-PVA from drawn PVTFA film saponified with gaseous ammonia intending to prepare high performance s-PVA.

Experimental. Vinyl trifluoroacetate (VTFA) was synthesized through the reaction of acetylene with trifluoroacetic acid. The thermal polymerization and photo-polymerization were carried out at 60 and $-78^{\circ} \mathrm{C}$ in pyrex tubes using benzoyl peroxide of $0.05 \%$ and tetrahydrofuran $(4.8 \mathrm{vol} \%)$-benzophenone $(0.05 \%)$ respectively. PVTFA was recovered by dissolving the polymerization mixture in acetone followed by precipitation in petroleum ether. The PVTFA obtained through thermal polymerization is named PVTFA-T and that through photo-polymerization PVTFA-L. The degrees of polymerizations determined by viscometry for the polymers saponified with gaseous ammonia followed by acetylation are 2130 for PVTFA$\mathrm{T}$ and 2370 for PVTFA-L. The stereoregularities of 
Table I. Dissolution temperatures of saponified PVA films in water

\begin{tabular}{lccc}
\hline & \multicolumn{2}{c}{$\begin{array}{l}\text { Treatment } \\
\text { conditions }\end{array}$} & \multicolumn{2}{c}{$\begin{array}{c}\text { Dissolution } \\
\text { temp. }{ }^{\circ} \mathrm{C}\end{array}$} \\
\hline $\begin{array}{l}\text { Before } \\
\text { saponifn. }\end{array}$ & $\begin{array}{l}\text { After } \\
\text { saponifn. }\end{array}$ & PVTFA-T & PVTFA-L \\
\hline UD & - & 100 & 130 \\
UD & HT & 110 & 140 \\
D4×,HT1h. & - & 120 & 140 \\
D4×,HT1h. & HT & 120 & 160 \\
\hline
\end{tabular}

UD: undrawn. D: drawn. HT: heat-treated.

Table II. Stereoregularities of saponified PVA samples

\begin{tabular}{lllcc}
\hline & & \multicolumn{3}{c}{ Triad } \\
\cline { 3 - 5 } & Saponifn. & $\mathrm{I}$ & $\mathrm{H}$ & $\mathrm{S}$ \\
\hline \multirow{2}{*}{ PVTFA-T } & $\mathrm{DADET}$ & 16.2 & 49.6 & 34.2 \\
& $\mathrm{NH}_{3}$ & 14.2 & 51.0 & 34.7 \\
\hline \multirow{2}{*}{ PVTFA-L } & $\mathrm{DADET}$ & 13.8 & 44.4 & 41.8 \\
& $\mathrm{NH}_{3}$ & 13.5 & 45.5 & 41.0 \\
\hline
\end{tabular}

DADET: 2,2' diaminodiethyltriamine.

the samples were determined using a Brucker $500 \times \mathrm{D}$ NMR spectrometer and $d_{6}$-DMSO as solvent as shown in Table II. As-cast films and the films prepared by stretching at $100^{\circ} \mathrm{C}$ to various extensions after casting from acetone solutions were tautly treated with dry gaseous ammonia for $3 \mathrm{hrs}$. at room temperature at once or after heat-setting at $100^{\circ} \mathrm{C}$ taut for $1 \mathrm{hr}$., and then washing with methanol followed by drying in vacuum at room temperature. The IR spectrum and $\mathrm{X}$-ray photographs of the saponified samples were taken with a Nippon Bunko FTIR spectrometer and a Shimazu X-ray camera, respectively. The degree of crystallization of a saponified sample was estimated from the density determined by a floating method. ${ }^{14)}$

Results. Figs. 1a and b show the IR spectrum of s-PVA prepared by the saponification of undrawn and drawn (drawn 4 times and then annealed at $100^{\circ} \mathrm{C}$ taut for $1 \mathrm{hr}$.) PVTFA-T and PVTFA-L respectively. Both figures indicate that the intensity of crystallization sensitive band at $1144 \mathrm{~cm}^{-1}$ of the film prepared from drawn PVTFA is lower than that prepared from undrawn PVTFA and in the content of apparent racemic sequence, $\mathrm{r}(\%)$ estimated from the IR spectrum using the equation ${ }^{15}$ a)

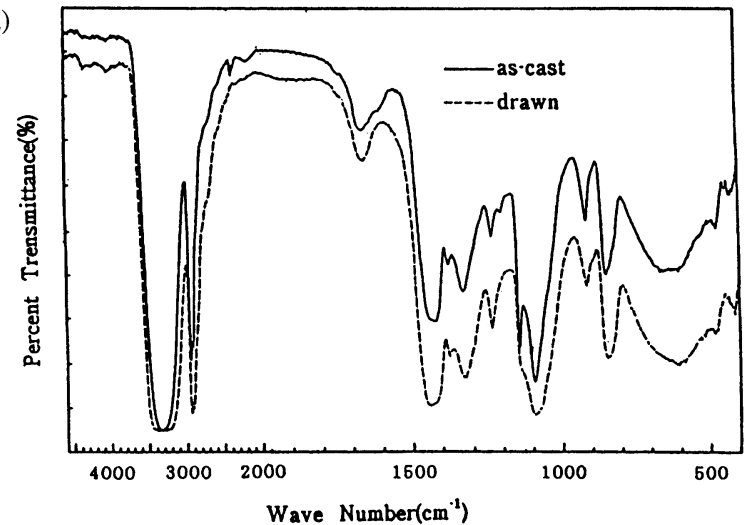

b)

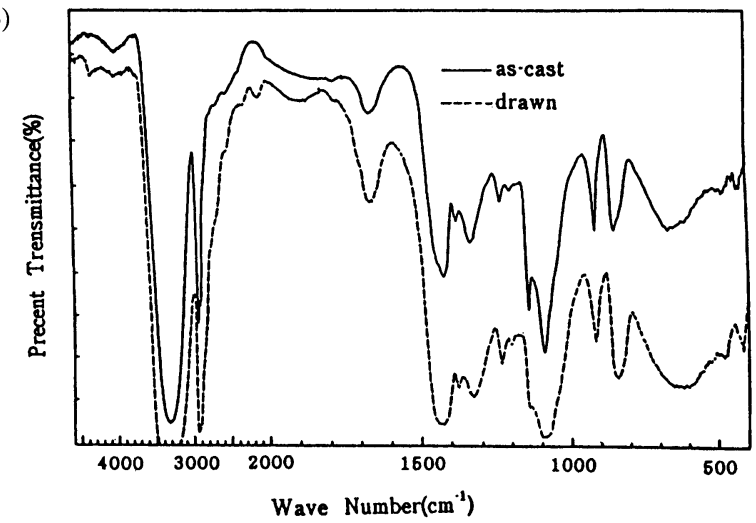

Fig. 1. Change of the intensities of crystallization (1144 $\left.\mathrm{cm}^{-1}\right)$ and racemic diad $\left(916 \mathrm{~cm}^{-1}\right)$ sensitive bands of s-PVA films with drawing (4 times and annealing at $100^{\circ} \mathrm{C}$ for $1 \mathrm{hr}$.) before saponification. a) s-PVA from PVTFA-T, b) s-PVA from PVTFA-L.

$$
\mathrm{r}(\%)=72.4 \times\left(\mathrm{D}_{916} / \mathrm{D}_{847}\right)^{0.43}
$$

the similar relation is recognized, i.e. $\mathrm{r}(\%)$ changed from 59 to $43 \%$ in PVTFA-T and 64 to $58 \%$ in PVTFA-L due to stretching before saponification, respectively. The intensities of crystallization and racemic diad sensitive bands in infrared absorption spectra of the s-PVA films decreased with increasing heat-drawing ratio before saponification. The band at $916 \mathrm{~cm}^{-1}$ is sensitive to tacticity and assigned to C-C stretching vibration ${ }^{15)}$ and the intensity has been described to decrease with heat-treatment accompanying the increase in the intensity at $1144 \mathrm{~cm}^{-1}$, i.e., the increase in the degree of crystallization. ${ }^{9)}$ The results obtained here suggest the formation of hydrogen bonds without crystallization. Figs. 2a and b show the variation of the intensity of the $1144 \mathrm{~cm}^{-1}$ band with heating of the s-PVAs prepared from undrawn and drawn PVTFA-T at $200^{\circ} \mathrm{C}$ respectively. Fig. 3 shows the dependencies of the apparent $r(\%)$ of 
a)

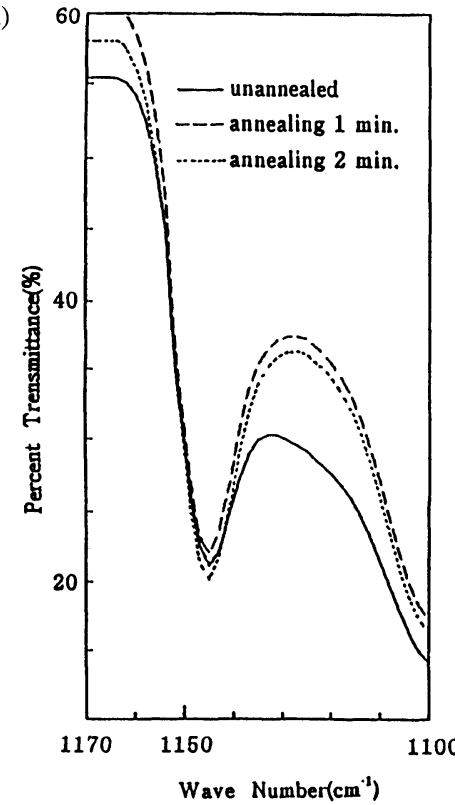

b)

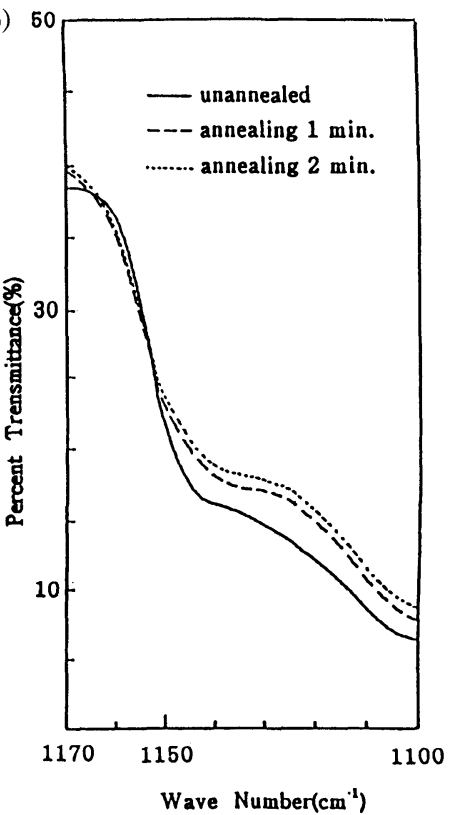

Fig. 2. Change of the intensities of crystallization sensitive bands of s-PVA films with heating. a) s-PVA from as-cast PVTFA-T film, b) s-PVA from drawn (drawn 4 times and annealed at $100^{\circ} \mathrm{C}$ for $1 \mathrm{hr}$.) PVTFA-T film.

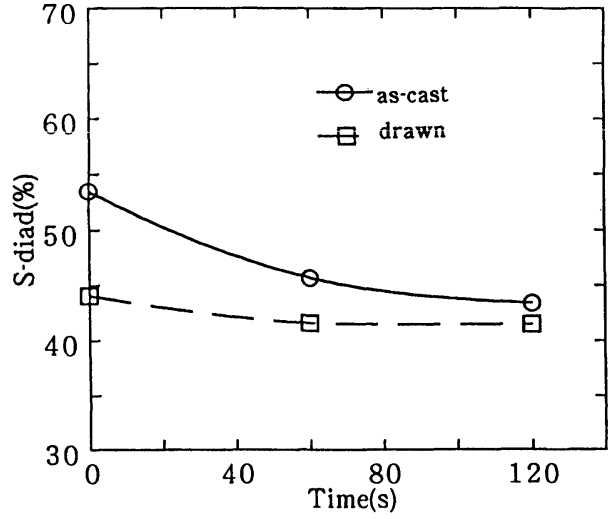

Fig. 3. Dependencies of apparent racemic diad contents of s-PVA films derived from as-cast $(\bigcirc)$ and drawn, ( $\square$ ) (4 times and annealed at $100^{\circ} \mathrm{C}$ for $1 \mathrm{hr}$.) PVTFA-T film on heating time.

the two kinds of PVA films on heating time. In the s-PVA prepared from undrawn PVTFA-T the intensity at $1144 \mathrm{~cm}^{-1}$ band increased and the apparent $\mathrm{r}(\%)$ decreased whereas in the s-PVA prepared from drawn PVTFA-T both almost did not change. The similar results were obtained for PVTFA-L. These results suggest that the s-PVA prepared from drawn PVTFA has too many hydrogen bonds to move segments at $200^{\circ} \mathrm{C}$. Figs. $4 \mathrm{a}$ and $\mathrm{b}$ show $\mathrm{x}$-ray photographs of the s-PVA prepared from drawn PVTFA-T and of the drawn c-PVA film. The s-PVA has small amounts of crystallites different from c-PVA. The degree of crystallization of the s-PVA prepared through the saponification of PVTFA-T heat drawn 7 times was $29 \%$. The solubilities of the s-PVA films are shown in Table I. The solubility decreased with drawing of PVTFA before saponification and heating of the s-PVA after saponification. The molecular orientation and the hydrogen bonds heightened the dissolving temperature. Table II shows the sequence distribution of the s-PVA samples saponified homogeneously with 2,2'-diaminodiethyl triamine (DADET) and that saponified with gaseous ammonia. No difference in stereoregularity is recognized between two kinds of s-PVA samples.

Conclusion. Solid s-PVA with low degree of crystallization but with high content of hydrogen bonds is prepared through the solid state saponification of heat-drawn PVTFA with gaseous ammonia. This might be concerned with the state of molecular aggregates of PVTFA. 
a)

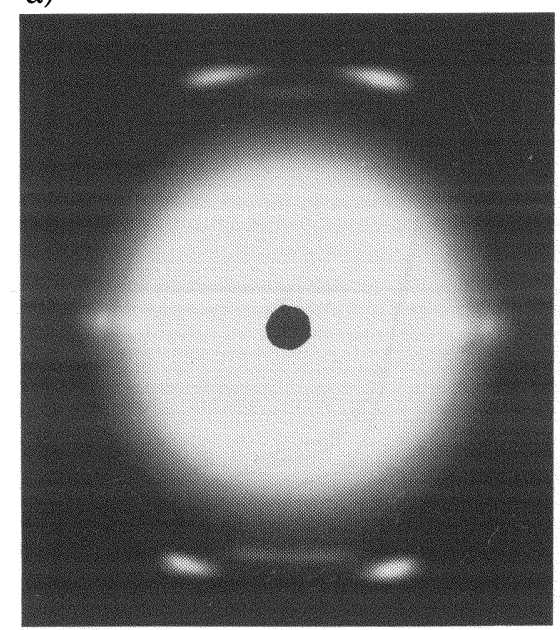

b)

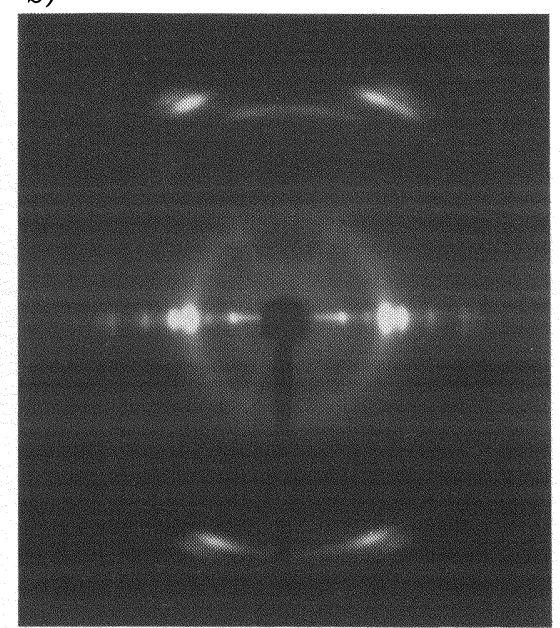

Fig. 4. X-ray photographs. a) s-PVA prepared through the saponification in solid state of PVTFA-T drawn 7 times at $100^{\circ} \mathrm{C}$ (annealed at $200^{\circ} \mathrm{C}$ ), b) c-PVA drawn 7 times at $200^{\circ} \mathrm{C}$ (annealed at $200^{\circ} \mathrm{C}$ ).

\section{References}

1) Haas, H. C., Emerson, E. S., and Schuler, N. W. (1956) J. Polym. Sci. 22, 291-302.

2) Itoh, T., Noma, K., and Sakurada, I. (1959) Koubunshi Kagaku 16, 115-119.

3) Imai, K., and Matsumoto, M. (1961) J. Polym. Sci. 55, 335-342.

4) Tincher, W. C. (1965) Makromol. Chem. 85, 46-57.

5) Ramey, K. C., and Field, N. D. (1965) J. Polym. Sci., Polymer Letters 3, 63-67.

6) Murahashi, S., Nozakura, S., Sumi, M., Yuki, H., and Hatada, K. (1965) Koubunshi Kagaku 23, 605-612.

7) Tanigami, T., Shirai, Y., Yamaura, K., and Matsuzawa, S. (1994) Polymer 35, 1970-1976.

8) Hanatani, H. (1994) Thesis. Faculty of Textile Science and
Technology, Shinshu University.

9) Sumi, M., Matsumura, K., Ohno, R., Nozakura, S., and Murahashi, S. (1967) Koubunshi Kagaku 24, 606-613.

10) Smith, P., and Lemstra, P. J. (1980) J. Mater. Sci. 15, 505-514; Kunugi T., Oomori, S., and Mikami, S. (1988) Polymer 29, 814-820.

11) Cha, W.-I., Hyon, S.-H., and Ikada, Y. (1994) J. Polym. Sci., Polym. Phys. 32, 297-304.

12) Okazaki, M., Miyasaka, N., and Matsuzawa, S. (1995) Koubunshi Ronbunshu 52, 710-717.

13) Bohn, C. R., Schaefgen, J. R., and Statton, W. O. (1961) J. Polym. Sci. 55, 531-549.

14) Sakurada, I., Nukushina, Y., and Sone, Y. (1955) Koubunshi Kagaku 12, 506-510.

15) Tadokoro, H., Seki, S., Nitta, I., and Yamadera, R. (1958) J. Polym. Sci. 28, 244-247. 